\title{
ANL/ER/PP- -86709 \\ MICROWAVE DISSOLUTION OF PLANT TISSUE AND THE SUBSEQUENT DETERMINATION OF TRACE LANTHANIDE AND ACTINIDE ELEMENTS BY INDUCTIVELY COUPLED PLASMA-MASS SPECTROMETRY
}

\author{
Jorge S. Alvarado $\dagger^{1}$, Teresa J. Neal*, Lesa L. Smith ${ }^{2}$, and M.D. Erickson ${ }^{1}$
}

Environmental Research Division ${ }^{1}$ and Chemical Technology Division ${ }^{2}$

Argonne National Laboratory

Argonne, IL 60439

† To whom correspondence should be addressed.

* Present address: Department of Chemistry and Biochemistry, University of Notre Dame, Notre Dame, IN 46556.

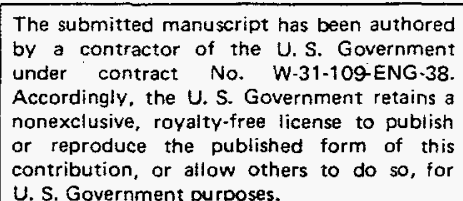

Work supported by the U.S. Department of Energy, Assistant Secretary for Environmental Management, EM-263, under contract W-31-109-Eng-38. 


\section{DISCLAMMER}

Portions of this document may be illegible in electronic image products. Images are produced from the best available original docament. 


\begin{abstract}
Recently there has been much concern with the ability of plants to uptake heavy metals from their surroundings. With the development of instrumental techniques with low detection limits such as inductively coupled plasma-mass spectrometry (ICP-MS), attention is shifting toward achieving faster and more elegant ways of oxidizing the organic material inherent in environmental samples. Closed-vessel microwave dissolution was compared with conventional methods for the determination of concentrations of cerium, samatium, europium, terbium, uranium and thorium in a series of samples from the National Institute of Standards and Technology and from fields in Idaho. The ICP-MS technique exhibited detection limits in partsper-trillion and linear calibration plots over three orders of magnitude for the elements under study. The results obtained by using nitric acid and hydrogen peroxide in a microwave digestion system for the analysis of reference materials showed close agreement with the accepted values. These values were compared with results obtained from dry-and wet-ashing procedures. The findings from an experiment comparing radiometric techniques for the determination of actinide elements to ICP-MS are reported.
\end{abstract}

\title{
DISCLAIMER
}

This report was prepared as an account of work sponsored by an agency of the United States Government. Neither the United States Government nor any agency thereof, nor any of their employees, makes any warranty, express or implied, or assumes any legal liability or responsibility for the accuracy, completeness, or usefuiness of any information, apparatus, product, or process disclosed, or represents that its use would not infringe privately owned rights. Reference herein to any specific commercial product, process, or service by trade name, trademark, manufacturer, or otherwise does not necessarily constitute or imply its endorsement, recommendation, or favoring by the United States Government or any agency thereof. The views and opinions of authors expressed herein do not necessarily state or reflect those of the United States Government or any agency thereof. 


\section{INTRODUCTION}

As a result of ongoing industrial pollution and the vital role of plants in the food chain, interest has increased in the ability of plants to uptake potentially hazardous heavy metals from their surroundings. Much attention has also been given to the field of radiological safety, including the determination of small amounts of actinide elements in botanical tissues, as a component of individual contamination-monitoring problems (1). Because environmental samples have large amounts of organic matrix elements but may have low concentrations of the rare earth elements, a digestion procedure whereby the organic matrix is oxidized, leaching the metals from the matrix, must be coupled with an instrumental technique with characteristically low limits of detection.

Problems typically arising from the determination of elements in environmental samples are not associated with the efficiency of the instrumental method, but rather with the sample preparation technique (2). Ironically, remarkable improvements have been made in instrumentation, but sample preparation methods have barely progressed. Specifically, the literature contains few references to apropos methods for separating lanthanide and actinide elements from organic matrices.

Inductively coupled plasma-mass spectrometry (ICP-MS) possesses several qualities that make it well suited for the analysis of plant tissue. The extremely low detection limits (typically $\mathrm{ng} / \mathrm{L}$ ), high resolution, high precision, short measurement time, and capacity for simultaneous trace multi-elemental and isotopic analyses of solutions make ICP-MS superior to many other techniques (3-4). In fact, the rare earth elements were one of the first groups of elements to be successfully determined by ICP-MS in a range of geologic materials (5). In determining the levels of rare earth elements by other techniques, such as atomic absorption spectroscopy, ICP-atomic emission spectroscopy, and X-ray fluorescence, spectral interferences necessitate the separation of this group of elements from their matrix. In comparison, for ICP- 
MS, the rare earth elements lie in the region of the mass spectrum that is characterized by minimal interferences and highest sensitivity (5).

Some laboratories have spent several hundreds of thousands of dollars to purchase an ICP-mass spectrometer but still prepare their samples by using a one hundred dollar hot plate (6). This method of digestion, called wet ashing, is a very slow process that requires considerable supervision. In addition, wet ashing can introduce huge amounts of background contamination because of the need for increased amounts of acids. The acids most commonly used in wet ashing are nitric acid and sulfuric acid. Nitric acid is a strong oxidizing agent that will liberate trace elements from many materials as highly soluble nitrate salts (1). Nitric acid is generally regarded as the "best" acid medium for ICP-MS analysis because the fundamental elements are already present in the air surrounding the plasma and because nitric acid is one of only a few acids that are easily obtained in high-purity form, making it ideal for work with ultratrace elements. A disadvantage of nitric acid is its characteristically low boiling point, demanding long digestion times or the addition of others acids to better destroy organic matrices. Because the addition of sulfuric acid raises the boiling point of the mixture and so enhances the action of the other oxidant, sulfuric acid is typically used in combination with nitric acid (1).

Dry ashing can be applied to the determination of most common metals and is considered by some analysts to be relative inexpensive and rapid (5). This method basically only requires the use of a muffle furnace and does not require supervision. Dry ashing can be used for large quantities of sample with the use of few reagents, but some trace elements may be lost because of volatilization. Although high temperatures must be maintained to complete the oxidation process, loss of metals by volatilization or by combination with the material of the container must be avoided by ashing at the lowest possible temperature.

Most conventional procedures for sample digestion (wet ashing or dry ashing) are burdensome, laborious, and potentially hazardous, such as the notorious perchloric acid digestion (7). Over the years, controversy has existed over the merits of the wet and dry oxidation procedures (1). The need to replace wet ashing and dry ashing with a faster, cleaner, and more 
reproducible technique that is free of external contamination has recently focused attention on the microwave oven as a means of sample dissolution $(6,8-11)$. The closed-vessel system allows increased pressure and higher digestion temperatures, reducing sample digestion times sometimes by a factor of ten (12). In addition, a larger sample can be analyzed allowing lower limits of detection for each isotope, a better "representativeness" of aliquots, and the monitoring of lowabundance isotopes by using classical radiometric techniques such as $\alpha$-spectrometry. The microwave is convenient not only because it can be programmed to complete digestion unattended, but also because automatic venting ensures that the vessel will not rupture because of expansion pressure. This method, because it takes place in a closed-vessel system, prevents the loss of volatile analytes and minimizes the risk of contamination from other samples or from the surroundings (12). Closed vessels reduce the production of hazardous fumes during digestion, which increases the lifetime of laboratory fume hoods (2). Very promising results have been obtained by using the microwave digestion procedure, although care must be taken in determining the size and matrix of the sample, the amount of acid to be used, and the operating power and time (13).

In this article microwave dissolution will be described. Environmental plant tissue, including standards from the National Institute of Standards and Technology (NIST) were digested by using microwave dissolution and were analyzed by ICP-MS. Percent recoveries and the concentrations of lanthanide and actinide elements such as cerium, samarium, europium, terbium, thorium, and uranium were studied. In addition a comparison of methods and improvements in sample dissolution are included.

\section{EXPERIMENTAL}

\section{Instrumentation:}

The ICP-mass spectrometer used in these investigation was a Fisons PlasmaQuad II (VG Elemental, Uxbridge, Middlesex, England). The nebulizer used was a glass dual concentric type 
(Glass Expansion Pty. Ltd., Australia). A water-cooled Scott double-pass spray chamber (also supplied by Fisons) was used in combination with the pneumatic nebulizer. Samples were transferred to the nebulizer by using a ten-roller peristaltic pump (Miniplus 3; Gilson Medical Electronics, Middleton, WI). Instrument operating conditions are listed in Table I.

Microwave digestion of plant samples was accomplished with a microwave oven (Milestone 1200 Mega; Buck Scientific, Italy). Microwave specifications and operating conditions are given in Table II.

\section{Sample Preparation:}

The plant tissues used were samples of various grasses and weeds from Idaho. Orchard leaves (SRM 1571) and apple leaves (SRM 1515) from the NIST that contained several known concentrations of trace elements were also used. Concentrations of thorium and uranium concentrations given by NIST for the orchard leaves were certified values for those elements; certified values are based on results obtained by reference methods of known accuracy and carried out by two or more analysts. All concentrations given by NIST for the apple leaves were noncertified concentrations. All samples of vegetation were placed in beakers, covered with watch glasses, and dried in a oven at $105^{\circ} \mathrm{C}$ for 24 hours. Upon removal from the oven, the samples were stored in a desiccator.

\section{Digestion Procedures:}

Dry Ashing: Two previously dried 2.0-g samples of each type of vegetation were weighed and placed into $150-\mathrm{mL}$ crucibles. The samples were spiked with $0.20 \mathrm{~mL}$ of a $10 \mathrm{mg} / \mathrm{L}$ solution of thulium, $0.1 \mathrm{~mL}$ of a $5.93 \mathrm{pCi} / \mathrm{L}$ solution of $\mathrm{U}-236$, and $0.8 \mathrm{~mL}$ of a $15 \mathrm{pCi} / \mathrm{mL}$ solution of Th-229. Thulium was used as internal standard. Thorium and uranium were used for isotope dilution. The crucibles were placed into a muffle furnace (Lindberg, Watertown, WI) at $100^{\circ} \mathrm{C}$ for 1 hour. The temperature was increased $50^{\circ} \mathrm{C}$ every 30 minutes to a final temperature of $500^{\circ} \mathrm{C}$. The temperature was then maintained until ashing was completed. 
Wet Ashing: Two previously dried $2.0-\mathrm{g}$ samples were placed into 250 -mL beakers. Each sample was spiked with thulium, uranium-236, and thorium-229 by using the same volumes and concentrations described during the dry-ashing procedure. Thirty milliliters of nitric acid ultra pure (Ultrex II, J.T. Baker) and $10.0 \mathrm{~mL}$ of concentrated sulfuric acid (Ultrex, J.T. Baker) were added to each beaker. Beakers were placed onto a heated mantle, and the acid mixture was brought to a boil. The boiling temperature was maintained, allowing the acid solution to reflux for 2-3 hours.

Microwave Oven: Samples weighing from 0.5 to $3 \mathrm{~g}$ were placed into microwave digestion vessels. Each sample was spiked with thulium, uranium-236, and thorium-229 as previously described. To each vessel, 10 to $15 \mathrm{~mL}$ of $70 \% \mathrm{v} / \mathrm{v}$ nitric acid and $1.0 \mathrm{~mL}$ of $30 \%$ hydrogen peroxide were added. For small weights, samples were treated by using digestion program 1 as described in Table II. For samples heavier than $2 \mathrm{~g}$, digestion program 2 described in the same table was used. Before being opened, the vessels were allowed to cool in a water bath for at least 20 minutes.

\section{ICP-MS Measurements:}

Tuning and Data Acquisition: On each day of this study, the ICP-MS was started and allowed to equilibrate for about one hour. Mass calibration accuracy and short-term stability were tested by using a tune solution of $10 \mathrm{ppb} \mathrm{Be}, \mathrm{Mg}, \mathrm{Co}, \mathrm{Y}, \mathrm{In}, \mathrm{La}, \mathrm{Lu}, \mathrm{Pb}$, and $\mathrm{U}$.

All samples were acquired by multiple ion monitoring while the sample was pumped into the nebulizer. Each measurement consisted of 10 consecutive integrations, with each integration being $60 \mathrm{~s}$ in duration. An autosampler (Gilson, Inc., Middleton, WI) was used to introduce the sample.

Reagents: Standard solutions containing $1-\mathrm{g} / \mathrm{L}$ of cerium, samarium, europium, terbium, thulium, thorium, and uranium (from Aldrich Chemical Company, Inc., Milwaukee, WI) were used for this investigation. Aliquots of the standards were mixed and diluted volumetrically with 
$5 \% \mathrm{v} / \mathrm{v}$ nitric acid. The following dilutions were made: $10 \mu \mathrm{g} / \mathrm{L}(10 \mathrm{ppb}), 1 \mu \mathrm{g} / \mathrm{L}(1 \mathrm{ppb}), 100$ $\mathrm{ng} / \mathrm{L}(0.1 \mathrm{ppb}), 10 \mathrm{ng} / \mathrm{L}(0.01 \mathrm{ppb})$, and $1 \mathrm{ng} / \mathrm{L}(0.001 \mathrm{ppb})$.

Other Studies: In instances where all instrument parameters were held constant, a diluent blank was measured before the standard(s), such that background correction was performed by blank subtraction. A blank was also measured at the end of the procedure to assess the stability of the background. No significant changes in background were observed by this means.

\section{RESULTS AND DISCUSSION}

\section{Optimal Operating Conditions:}

Gas Flows: Nebulizer gas flow rate and sample uptake rate were studied. In these studies, the analyte solution was introduced continuously. Nebulizer gas flow and sample uptake were monitored by keeping all parameters constant while running several acquisitions at ranging nebulizer gas flow and uptake rate. Figure 1 shows the influence of the nebulizer argon flow rate on signal intensity. In all cases, the ion signal was maximized when the nebulizer flow was set at $0.84 \mathrm{~L} / \mathrm{min}$. At flow rates higher than $0.84 \mathrm{~L} / \mathrm{min}$, the signal decreased dramatically. Figure 2 shows the influence of sample uptake on signal intensity. A dramatic decrease in ion signal for all elements is seen at uptake rates higher than $1.7 \mathrm{~mL} / \mathrm{min}$.

\section{Linearity and Detection Limits:}

Samples of each element were introduced by using the pneumatic nebulization system. Figure 3 shows the response with increasing concentration for cerium, samarium, europium, terbium, thulium, and uranium-238. Linear responses are unique for each element. The response was linear for samarium, europium, thulium, and uranium when solution concentrations for each element ranging from 0.01 to $10 \mu \mathrm{g} / \mathrm{L}$ were studied. The log-log slopes for $\mathrm{Sm}, \mathrm{Eu}, \mathrm{Tm}$, and U238 were $0.998,0.982,0.981$ and 1.012 , respectively. A "rollover" at high concentrations was 
observed for cerium and terbium. The log-log slope for these elements was 0.906 and 0.926 , respectively. These observations can be explained by a combination of effects. The first effect is overloading of the plasma and, as a consequence, a reduction in the temperature, desolvation rates, and atomization/ionization efficiencies. The second effect is the formation of stable oxides, which are difficult to atomize when they are present in high concentrations. For all elements in the study, the log-log calibration plots had correlation coefficients $\left(\mathrm{r}^{2}\right)$ higher than 0.99 .

Detection limits were obtained and the results are listed in Table III. The limits of detection are defined as three times the pooled standard deviation (e.g., internal precision) of 10 nonconsecutive blank analyses performed on three different days. The detection limits ranged from 0.1 to $0.9 \mathrm{ng} / \mathrm{L}$.

\section{Microwave Dissolution:}

Microwave procedures are used to speed the dissolution of solid samples by combining the rapid heating ability of microwave energy with the advantages inherent in the use of sealed digestion vessels. Some advantages of microwave dissolution include (1) the ability to decrease the dissolution time by increasing reaction rates, (2) a more controlled dissolution process, and (3) being more amenable to automation than conventional open beakers or closed-vessel techniques. Because the microwave procedure proved to be a convenient means of dissolution, different mixtures of acids, microwave power, and time were examined to determine which conditions are best used for digestion of vegetation. The conditions described in Table II were found to be best for the analysis of up to 3-g samples.

Samples of orchard leaves (SRM-1571) and apple leaves (SRM-1515) from NIST were studied. A preliminary study was performed on the effect of using higher power on the dissolution of the sample and to find the optimum conditions for complete extraction of actinide and lanthanide elements. The power was increased from 400 to $700 \mathrm{~W}$ for a total time of $5 \mathrm{~min}$. Statistically, no differences were observed in the results when the power was increased. For safety and fast dissolution, $600 \mathrm{~W}$ was found to be satisfactory. To quantify radioisotopes that 
are only found at low concentrations in nature, the effect of sample size on the resulting concentration was determined. Samples of orchard leaves and apples leaves were used to analyze the concentration of cerium, samarium, europium, terbium, thorium, and uranium. Digestion procedure 2 from Table II was shown to be optimum when the sample size was increased. Sample size was increased to allow detection of minor isotopes such as U-235, U-234 and Th230 , and the calculation of its isotopic ratios. A larger sample size will improve detection limits and will allow monitoring low-abundance isotopes in the environment. This information will show preconcentration effects, uptake rates, and pollution levels when comparing those results with blank samples and concentrations of the soils in the surrounding areas. Table VII shows values for U-235 and U-234 by. ICP-MS and $\alpha$-spectrometry. Detection limits for these elements were calculated to be 0.8 and $0.7 \mathrm{ng} / \mathrm{L}$, respectively, by using pneumatic nebulization and ICP-MS. For this experiment, 3-g samples were complete digested, and the results were compared with the results obtained by using other sample sizes.

The uncertified concentrations of $\mathrm{Ce}, \mathrm{Sm}, \mathrm{Eu}, \mathrm{Tb}, \mathrm{Th}$, and $\mathrm{U}$ for apple leaves are presented in Table IV, along with the mean concentrations (and relative errors) of the same elements from the three digestion procedures. The certified concentrations for $\mathrm{Th}$ and $\mathrm{U}$ from orchard leaves are presented in Table V. As a general trend for all of the lanthanide elements, the values for the wet-ashing, dry-ashing and microwave procedures tend to agree with the standard values. For actinide elements, the dry-ashing and wet-ashing procedures tended to give lower values, as in Th-232 for orchard leaves, or tend to give higher values than the standard reference, as in U-238 for apple leaves. These values can be explained by the poor dissolution of the sample matrix in the case of the orchard leaves or by the introduction of external contamination by the digestion reagents in the case of apple leaves. The results with microwave dissolution compare with those obtained by dry-ashing and wet-ashing procedures. Table VI shows the percent recoveries of the sample spikes with each individual procedure. The microwave dissolution method gave the best recoveries for each sample and each spike. 
A lower result than the reported value was observed for Th-232 and U-238 for the orchard leaves. Several attempts were made to investigate the discrepancies. The certified sample from NIST was analyzed by using total dissolution. In this process, the organic and inorganic components (e.g., dust or soil particles) are dissolved into the solution and contribute to the total amount of actinides in the sample. In the microwave-oven dissolution using hydrogen peroxide and nitric acid, our hypothesis is that only the organic matrix is destroyed, leaving those inorganic particles insoluble and as a consequence, a lower value will be expected. Total dissolution was accomplished by fusing the sample in a muffle furnace for 12 hours and then dissolution by using a mixture 1:1 of hydrofluoric acid and nitric acid was used. Results are shown in Table VII. These results, show that no significant differences are seen when microwave dissolution or total dissolution is used. The authors are not aware of other studies where orchard leaves from NIST were analyzed for actinide elements. A bias in the result was observed through out this experiment for that specific sample.

Another result from the total dissolution of the samples is that microwave dissolution produced a complete equilibration of the samples and spike isotopes. Such equilibrium requires complete sample decomposition, during which spike integrity is maintained. Complete dissolution is also necessary to ensure that all components of various isotopic compositions within a sample are subsequently analyzed. Tables IV through VI show no statistically significant differences in the results between using microwave dissolution or total dissolution.

Table VIII contains the mean concentrations and relative errors determined by ICP-MS and by radiological methods for the various samples of vegetation taken from a site in Idaho. No known values were available for any elements except thorium for these samples. Several of these samples of vegetation vegetations has been analyzed previously by using a radiological method after dry ashing the sample. In the samples, ICP-MS showed higher sensitivity and lower uncertainty than the results obtained by $\alpha$-spectrometry in a 1000 -min counting time. 


\section{Methods Comparison:}

In deciding on a method of dissolution to employ, the advantages and disadvantages of each must be carefully determined. Ultimately, the percent recovery of a spike sample should be as close to $100 \%$ as possible. The average percent recovery for each method showed that the wet-ashing procedure had the lowest percent recovery at $30-60 \%$. The dry-ashing and microwave techniques had average percent recoveries of $80-90 \%$ and $83-99 \%$, respectively.

The amount of reagents used is also a concern. For each 2-g sample, the wet-ashing procedure required $40 \mathrm{~mL}$ of concentrated acids. The dry-ashing and microwave procedures required one-eighth of that amount of acid. The comparatively high concentrations in the wetashing procedure were attributed to the large amounts of preconcentrated acids that were used in the digestion procedure. Not only is the waste from wet-ashing more difficult to dispose, but it can also be the cause of contamination problems.

The rise in popularity of ICP-MS for multielement analysis in environmental samples has led to the need for an accurate technique for preparing large numbers of samples in a short period of time (13). In comparing the approximate time for dissolution, the microwave procedure was superior to other methods. The average time for 22 samples with dry-ashing was 28 hours, and with wet-ashing was 10 hours but for microwave dissolution was only 1 hour. In comparing only experimental results with known concentrations, the dry-ashing procedure is adequated, although time consuming. In deciding in a type of dissolution on the basis of the percent recovery or isotope dilution equilibration, the amount of reagent used in the dilution, and the digestion time, the microwave procedure outweighs the wet- and dry- ashing procedures. The microwave procedure is appealing to the analyst for many reasons: the digestion time is extremely low compared with others methods, the closed vessels generally eliminate the possibility of contamination, recoveries are comparable to other methods, and small amounts of acids are needed. 


\section{CONCLUSIONS}

The "best" dissolution procedure is one with high percent recoveries, reduced amounts of acids for dissolution, minimal time for analysis and low potential for contamination. Many analysts still rely on hot-plate methods, which have proven to have low percent recoveries, use a large amount of acids, require constant supervision, and have a high potential for contamination. The dry-ashing method proved to be an adequate means of determining concentrations of heavy metals in samples of vegetation, although the preparation time is twenty times longer than the microwave method and three times longer than the wet-ashing procedure. Dry-ashing has several advantages, including limited supervision and high percent recoveries. The microwave procedure is a very promising method with high relative percent recoveries, very little digestion time, almost no require supervision and an extremely low potential for contamination.

Inductively coupled plasma-mass spectrometry is a powerful tool for ultrasensitive multielemental trace analysis. Specifically, the rare earth elements are a difficult group to quantify by many analytical techniques, resulting in increasing attention being given to ICP-MS. Because each rare earth element has at least one isotope free of isobaric overlap and there are no molecular overlaps, the spectra are easily interpreted (5). New dissolution methods are still needed to keep up with the extremely sensitive instrumental techniques.

\section{Acknowledgments:}

The authors thank M. Carter and J. Poppiti for their support of this work. This work was funded by the Laboratory Management Division of the Office for Environmental Management, U. S. Department of Energy. Argonne National Laboratory is operated by the University of Chicago for the U. S. Department of Energy under contract W-31-109-Eng-38. 


\section{REFERENCES}

1. Gorsuch, T.T. The Destruction of Organic matter, Pergamon Press: Oxford, 1970.

2. Matusiewicz, H.; Sturgeon, R. Prog. Analyt. Spectrosc., 1989, 12, 21.

3. Morita, S.; Tobita, K.; Kurabayashi, M. Radiochim. Acta, 1993, 63, 63.

4. Lu, P.; Huang, K.; Jiang, S. Anal. Chem. Acta, 1993, 284, 181.

5. Jarvis, K.E.; Gray, A.L.; Houk, R.S. Handbook of Inductively Coupled Plasma Mass Spectrometry, Chapman and Hall: New York, 1992.

6. Gilman, L.; Engelhart W.G. Atomic Spectroscopy Advantages, 1990, 4, 14.

7. Smith, G.F. Anal. Chim. Acta, 1953, 8, 397.

8. Kokot, S.; King, G.; Keller, H.R.; Massart, D.L. Anal. Chim. Acta, 1992, 259, 267.

9. Lamothe, P.J.; Fries, T.L.; Consul, J.J. Anal. Chem., 1986, 58, 1881.

10. Kammin, W.R.; Brandt, M.J. Spectrosc., 1988,4, 49.

11. Trato, M.E. Environm. Lab., 1991, 28.

12. Gilman, L; Leblanc, G.N.; Revesz, R. Preparation of Environmental Samples for Metal Analysis Using Microwave Digestion, CEM Corp., Matthews, NC.

13. Bettinelli, M.; Baroni, U.; Partorelli, N. Anal. Chem. Acta, 1989, 225, 159. 
Table I. Operating Conditions for ICP-MS

Parameter

Incident power $(\mathrm{W})$

Reflected power (W)

Coolant (argon) flow ( $\left.\mathrm{L} \mathrm{min}^{-1}\right)$

Auxiliary (argon) flow ( $\left.\mathrm{L} \mathrm{min}^{-1}\right)$

Nebulizer (argon) flow ( $\left.\mathrm{L} \mathrm{min}^{-1}\right)$

Sample uptake $\left(\mathrm{mL} \mathrm{min}^{-1}\right)$

Ion optical voltages

Extractor

Collector

Lens 1

Lens 2

Lens 3

Lens 4

Pole bias

Vacuum (operating state)

Expansion (mbar)

Intermediate (mbar)

Analyzer (mbar)

\section{Setting}

1350

0

13.75

0.95

0.84

1.73

$-206$

$-5.10$

$-3.93$

$-28.24$

2.76

$-44.10$

$-0.48$

$2.0 \times 10^{0}$

$1.0 \times 10^{-4}$

$1.5 \times 10^{-6}$ 
Table II. Microwave Specifications and Operating Conditions

Microwave type

Digestion vessel

Programming

Digestion program 1

Sample size

Reagents

Step 1

Step 2

Step 3

Step 4

Digestion program 2

Sample size

Reagents:

Step 1

Step 2

Step 3

Step 4

Step 5

Step 6

Step 7

Step 8

Step 9

Step 10
Milestone 1200 Mega

Teflon closed vessel with safety

valve opening at $\approx 1500 \mathrm{psi}$

Programmable for power $(0-1200 \mathrm{~W})$ and time.

$0.5-0.75 \mathrm{~g}$

$10.0 \mathrm{~mL} \mathrm{70 \% (v/v)} \mathrm{nitric} \mathrm{acid}$

$1.0 \mathrm{~mL} \mathrm{30 \%} \mathrm{hydrogen} \mathrm{peroxide}$ $250 \mathrm{~W}$ for $2 \mathrm{~min}$

$0 \mathrm{~W}$ for $2 \mathrm{~min}$

$600 \mathrm{~W}$ for $5 \mathrm{~min}$

$0 \mathrm{~W}$ for $5 \mathrm{~min}$

$2-3 \mathrm{~g}$

$15.0 \mathrm{~mL} 70 \%(\mathrm{v} / \mathrm{v})$ nitric acid $1.0 \mathrm{~mL} 30 \%$ hydrogen peroxide $100 \mathrm{~W}$ for $2 \mathrm{~min}$

$0 \mathrm{~W}$ for $2 \mathrm{~min}$

$100 \mathrm{~W}$ for $2 \mathrm{~min}$

$0 \mathrm{~W}$ for $2 \mathrm{~min}$

$250 \mathrm{~W}$ for $2 \mathrm{~min}$

$0 \mathrm{~W}$ for $2 \mathrm{~min}$

$250 \mathrm{~W}$ for $2 \mathrm{~min}$

$0 \mathrm{~W}$ for $2 \mathrm{~min}$

$600 \mathrm{~W}$ for $5 \mathrm{~min}$

$0 \mathrm{~W}$ for $5 \mathrm{~min}$ 
Table III. Limits of Detection for Actinide and Lanthanide Elements

\begin{tabular}{lc}
\hline Element & Detection Limits $(\mathbf{n g} / \mathbf{L})^{\mathbf{a}}$ \\
\hline Cerium & 0.7 \\
Samarium & 0.9 \\
Europium & 0.3 \\
Terbium & 0.1 \\
Thulium & 0.1 \\
Th-232 & 0.7 \\
U-236 & 0.8 \\
U-238 & 0.2 \\
\hline
\end{tabular}

a Detection limits for "peak jump" acquisition with use of pneumatic nebulization for sample introduction. Limits of detection is three times the internal standard deviation of 10 nonconsecutive analyses, performed on three different days. 
Table IV. Concentrations of Elements in NIST Apple Leaves by Three Digestion Procedures

\begin{tabular}{lllll}
\hline Element & $\begin{array}{c}\text { Reported } \\
\text { Value } \\
(\mu \mathbf{g} / \mathbf{g})\end{array}$ & $\begin{array}{c}\text { Wet } \\
\text { Ashing } \\
(\mu \mathbf{g} / \mathbf{g})\end{array}$ & $\begin{array}{c}\text { Dry } \\
\text { Ashing } \\
(\mu \mathbf{g} / \mathbf{g})\end{array}$ & $\begin{array}{c}\text { Microwave } \\
\text { Oven } \\
(\mu \mathbf{g} / \mathbf{g})\end{array}$ \\
\hline $\mathrm{Ce}$ & $3 \pm 1^{\mathrm{a}}$ & $3.7 \pm 0.3$ & $4.1 \pm 0.3$ & $3.4 \pm 0.2$ \\
$\mathrm{Sm}$ & $3 \pm 1^{\mathrm{a}}$ & $2.8 \pm 0.3$ & $3.1 \pm 0.2$ & $2.6 \pm 0.2$ \\
$\mathrm{Eu}$ & $0.2 \pm 0.1^{\mathrm{a}}$ & $0.27 \pm 0.03$ & $0.31 \pm 0.03$ & $0.27 \pm 0.01$ \\
$\mathrm{~Tb}$ & $0.4 \pm 0.1^{\mathrm{a}}$ & $0.39 \pm 0.03$ & $0.43 \pm 0.04$ & $0.39 \pm 0.02$ \\
$\mathrm{Th}-232$ & $0.03 \pm 0.01^{\mathrm{a}}$ & $0.011 \pm 0.005$ & $0.025 \pm 0.003$ & $0.022 \pm 0.001$ \\
$\mathrm{U}-238$ & $0.006 \pm 0.001^{\mathrm{a}}$ & $0.0077 \pm 0.0007$ & $0.0072 \pm 0.0006$ & $0.0060 \pm 0.0003$ \\
\hline
\end{tabular}

a Uncertified concentrations for NIST apple leaves. 
Table V. Concentrations of Elements in NIST Orchard Leaves for Three Digestion Procedures

\begin{tabular}{lcccc}
\hline Element & $\begin{array}{c}\text { Reported } \\
\text { Value } \\
(\mu \mathbf{g} / \mathbf{g})\end{array}$ & $\begin{array}{c}\text { Wet } \\
\text { Ashing } \\
(\mu \mathbf{g} / \mathbf{g})\end{array}$ & $\begin{array}{c}\text { Dry } \\
\text { Ashing } \\
(\mu \mathbf{g} / \mathbf{g})\end{array}$ & $\begin{array}{c}\text { Microwave } \\
\text { Oven } \\
(\mu \mathbf{g} / \mathbf{g})\end{array}$ \\
\hline Cerium & $-\mathrm{a}$ & $1.01 \pm 0.02$ & $1.08 \pm 0.08$ & $1.1 \pm 0.2$ \\
$\mathrm{Sm}$ & $-\mathrm{a}$ & $0.10 \pm 0.01$ & $0.11 \pm 0.03$ & $0.11 \pm 0.02$ \\
$\mathrm{Eu}$ & $-\mathrm{a}$ & $0.025 \pm 0.002$ & $0.031 \pm 0.002$ & $0.040 \pm 0.003$ \\
$\mathrm{~Tb}$ & $-\mathrm{a}$ & $0.013 \pm 0.002$ & $0.014 \pm 0.001$ & $0.015 \pm 0.001$ \\
$\mathrm{Th}-232$ & $0.064 \pm 0.006^{\mathrm{b}}$ & $0.030 \pm 0.002$ & $0.039 \pm 0.008$ & $0.048 \pm 0.003$ \\
$\mathrm{U}-238$ & $0.029 \pm 0.005^{\mathrm{b}}$ & $0.025 \pm 0.002$ & $0.027 \pm 0.006$ & $0.022 \pm 0.002$ \\
\hline
\end{tabular}

a Not available

$\mathrm{b}$ Certified concentrations for NIST orchard leaves. 
Table VI. Percent Recoveries Obtained by Using Three Different Digestion Procedures.

Sample/Element

Dry Ashing

Wet Ashing

Microwave Oven

Orchard leaves

$\begin{array}{lccc}\text { Tm } & 90 \pm 6 & 37 \pm 11 & 89 \pm 4 \\ \text { U-236 } & 83 \pm 7 & 63 \pm 6 & 83 \pm 8 \\ \text { Th-229 } & -a & -a & 93 \pm 9\end{array}$

Apple leaves

$\mathrm{Tm}$

$80 \pm 3$

U-236

$72 \pm 8$

Th-229

-a

$34 \pm 13$

$99 \pm 3$

$40 \pm 20$

$94 \pm 3$

$-a$

$99 \pm 4$

a Not available. 
Table VII. Concentrations of Elements in NIST Orchard Leaves and Apple Leaves by ICP-MS and $\alpha$-Spectrometry

\begin{tabular}{|c|c|c|c|c|}
\hline \multirow[t]{3}{*}{ Element } & \multicolumn{4}{|c|}{$\begin{array}{l}\text { Total Dissolution } \\
\qquad(\mu \mathrm{g} / \mathrm{g}) \pm 2 \sigma^{\mathrm{a}}\end{array}$} \\
\hline & \multicolumn{2}{|c|}{ ICP-MS } & \multicolumn{2}{|c|}{$\alpha$-Spectrometry } \\
\hline & OL & $\mathrm{AL}$ & $\mathrm{OL}$ & $\mathrm{AL}$ \\
\hline Th-232 & $0.05 \pm 0.01$ & $0.027 \pm 0.001$ & $0.07 \pm 0.02$ & $0.04 \pm 0.02$ \\
\hline $\mathrm{U}-238$ & $0.026 \pm 0.006$ & $0.008 \pm 0.001$ & $0.04 \pm 0.02$ & $0.010 \pm 0.007$ \\
\hline $\mathrm{U}-235$ & $(2.1 \pm 0.7) \times 10^{-4}$ & $(6 \pm 2) \times 10^{-5}$ & b & $-b$ \\
\hline $\mathrm{U}-234$ & $(3 \pm 1) \times 10^{-6}$ & $(2 \pm 1) \times 10^{-6}$ & $(1.8 \pm 0.8) \times 10^{-6}$ & $(9 \pm 7) \times 10^{-7}$ \\
\hline
\end{tabular}

${ }^{a}$ Mean and standard deviations of the determination, where the standard deviation is derived from propagation of experimental uncertainty (ICP-MS) or counting statistics ( $\alpha$-spectrometry). ${ }^{b}$ U-236 used as internal standard for ICP-MS interfered with U-235 determination by $\alpha$ spectrometry $\mathrm{AL}=$ Apple Leaves; $\mathrm{OL}=$ Orchard Leaves. 
Table VIII. Concentrations of Thorium-232 in Grass Samples by Radiological and ICP-MS Detection Methods

\begin{tabular}{llll} 
Sample & $\alpha$-Spectrometry & \multicolumn{2}{c}{ ICP-MS } \\
\cline { 3 - 4 } & $\begin{array}{c}\text { Dry Ashing } \\
(\mu \mathbf{g} / \mathbf{g})\end{array}$ & $\begin{array}{c}\text { Dry Ashing } \\
(\mu \mathbf{g} / \mathbf{g})\end{array}$ & $\begin{array}{c}\text { Microwave Oven } \\
(\mu \mathrm{g} / \mathrm{g})\end{array}$ \\
\hline $93-8159-01$ & $0.009 \pm 0.018$ & $0.027 \pm 0.004$ & $0.024 \pm 0.002$ \\
$93-8159-03$ & $0.064 \pm 0.036$ & $0.067 \pm 0.012$ & $0.058 \pm 0.003$ \\
$93-8159-05$ & $0.009 \pm 0.018$ & $0.029 \pm 0.004$ & $0.025 \pm 0.002$ \\
$93-8159-06 \mathrm{~A}$ & $0.03 \pm 0.02$ & $0.031 \pm 0.004$ & $0.027 \pm 0.002$ \\
$93-8159-08$ & $0.02 \pm 0.02$ & $0.056 \pm 0.007$ & $0.067 \pm 0.005$ \\
$93-8159-09$ & $0.009 \pm 0.018$ & $0.018 \pm 0.002$ & $0.021 \pm 0.002$ \\
\hline
\end{tabular}




\section{List of Figures}

Figure 1 Variation in element signal as a function of solution uptake rate for cerium $(O)$, Samarium (x), Europium ( $\square$ ), Terbium ( $($ ) $)$, Thulium $(\diamond)$, and Uranium $(+)$.

Figure 2 Variation in element signal as a function of nebulizer gas flow rate for cerium ( $\square$ ), Samarium (x), Europium (+), Terbium ( () , Thulium (O), and Uranium( $(\mathbf{\square})$.

Figure 3 Calibration plots for Cerium $(\diamond)$, Samarium $(x)$, Europium $(\square)$, Terbium $(*)$, Thulium $(\diamond)$, and Uranium $(\mathrm{O})$. 


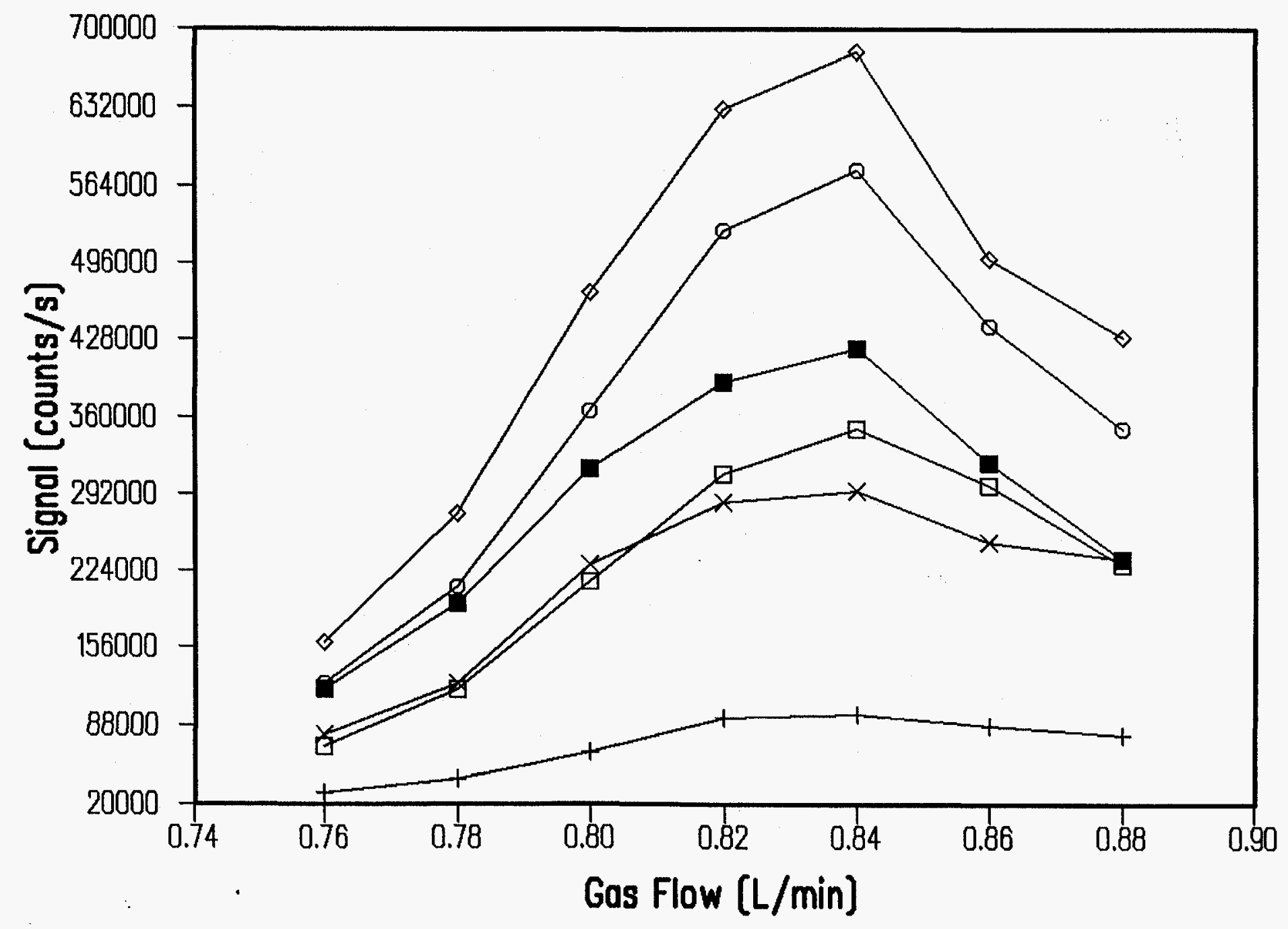

Figure 1 
产

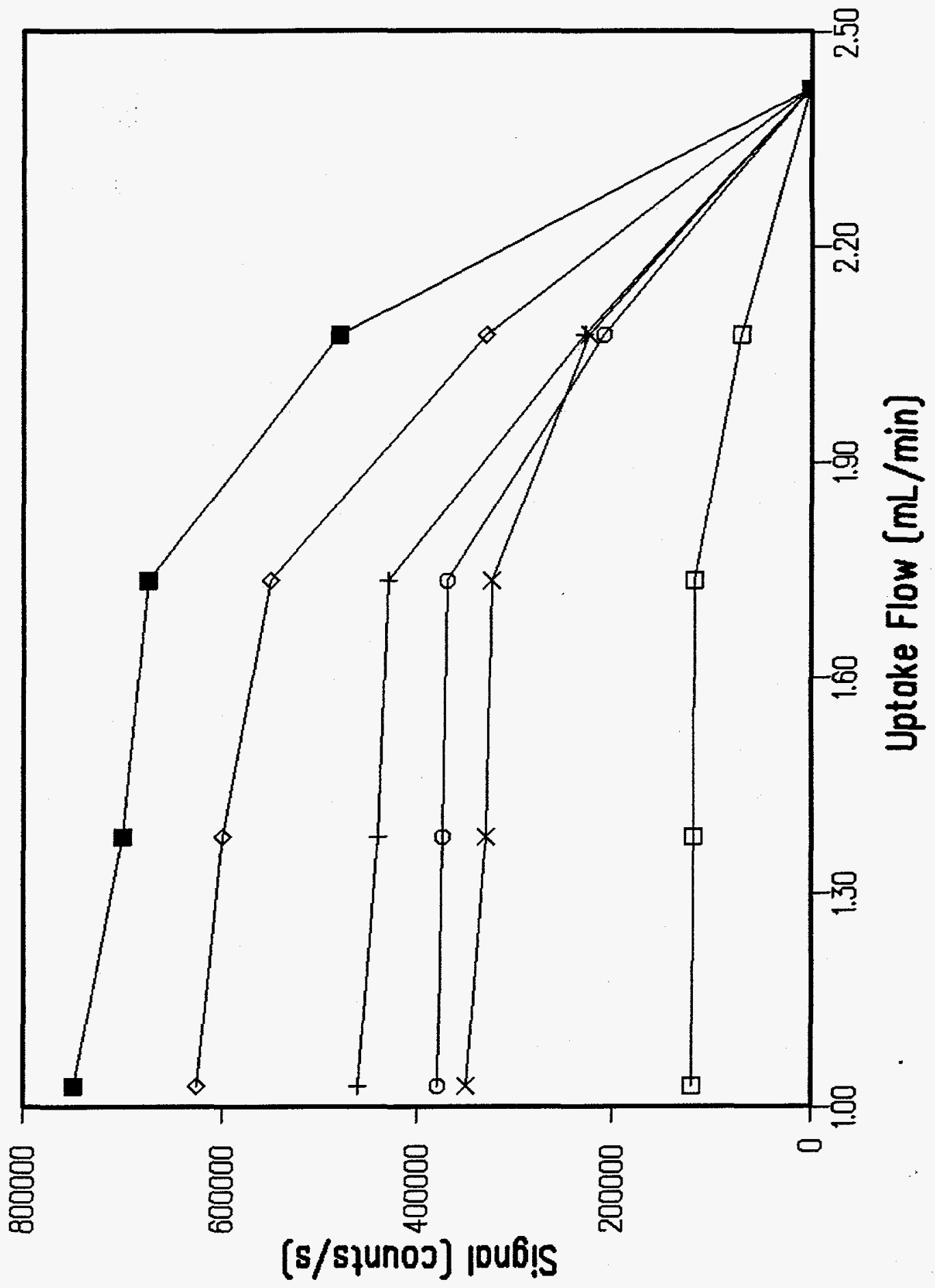




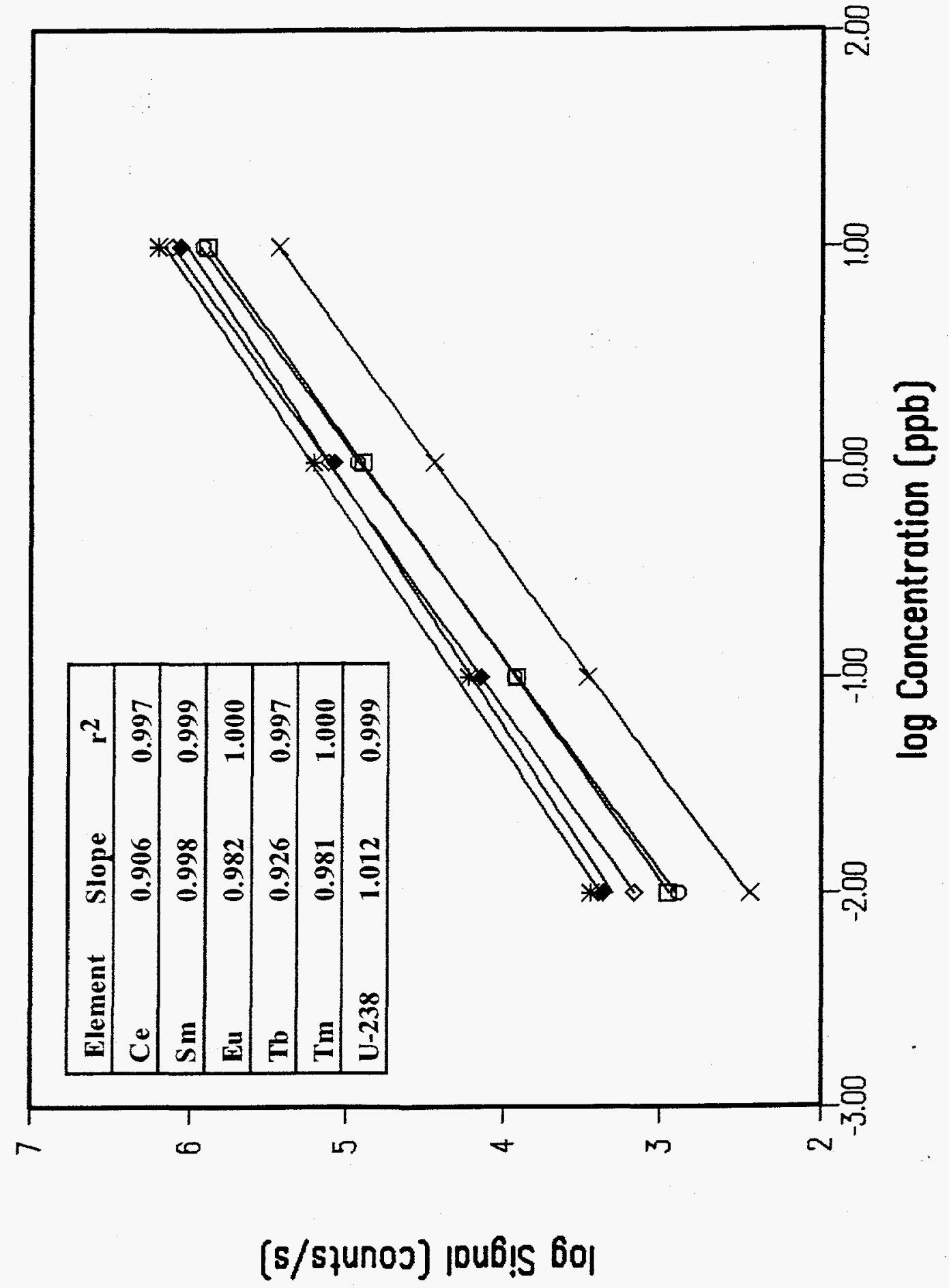

